BULLETIN Bulletin hispanique

HISPANIQUE Université Michel de Montaigne Bordeaux

115-1 | 2013

Poésie et société en Espagne : 1650-1750

\title{
Guillermo Carnero, Dibujo de la muerte: Obra poética
} 1966-1990

Cátedra, Madrid, 2010

\section{María Molina Delicado}

\section{(2) OpenEdition}

\section{Journals}

Edición electrónica

URL: http://journals.openedition.org/bulletinhispanique/2554

DOI: 10.4000/bulletinhispanique.2554

ISSN: 1775-3821

\section{Editor}

Presses universitaires de Bordeaux

\section{Edición impresa}

Fecha de publicación: 1 junio 2013

Paginación: 359-362

ISBN: 978-2-86781-898-1

ISSN: 0007-4640

Referencia electrónica

María Molina Delicado, «Guillermo Carnero, Dibujo de la muerte: Obra poética 1966-1990 », Bulletin hispanique [En línea], 115-1 | 2013, Publicado el 06 diciembre 2013, consultado el 19 abril 2019. URL http://journals.openedition.org/bulletinhispanique/2554

Este documento fue generado automáticamente el 19 abril 2019.

Tous droits réservés 


\title{
Guillermo Carnero, Dibujo de la muerte: Obra poética 1966-1990
}

Cátedra, Madrid, 2010

\author{
María Molina Delicado
}

\section{REFERENCIA}

Guillermo Carnero, Dibujo de la muerte: Obra poética 1966-1990. Madrid, Cátedra, 2010.

1 «Lo que sí es innegable es que la "pesadilla estética" anunciaba un cambio y que éste se ha producido más como ruptura que como evolución ${ }^{1} »$, dijo José María Castellet allá sobre los años 70 en Nueve Novísimos poetas españoles, la obra que encumbraría a los jóvenes que representaron el nacimiento de una nueva generación en la poesía. Dibujo de la muerte. Obra poética, el libro-antología de Guillermo Carnero -uno de los novísimos de Castellet nacido en Valencia en 1947- ante el que nos encontramos, ha sido reeditado por Ignacio Javier López en 2010, tras su primera edición en 1998. Con respecto a ésta, han sido añadidos nuevos poemas, en muchos de los casos por deseo expreso del autor, quien ha colaborado en la reedición.

2 «La inmortalidad es patrimonio de lo muerto»², escribe Carnero en su poema «Domus Área» perteneciente al libro de Variaciones y figuras sobre un tema de La Bruyère (1947) que se incluye en esta antología. La muerte como tema, como principio y como fin, e incluso como causa e innegable consecuencia de la propia vida, predomina ante todo en el primer apartado, correspondiente a la primera publicación del Dibujo de la muerte (1967), considerado rápidamente uno de los más relevantes libros de la nueva generación. En esta época Guillermo Carnero entabló amistad con un Jaime Gil de Biedma que sin duda le influyó notoriamente, a pesar de que los novísimos se autodefinan a sí mismos como la ruptura definitiva con todo lo anterior -poesía social de posguerra y Generación del 50pero, como se ve con claridad en Variaciones y figuras... la tradición siempre pesa en lo actual y no puede ser eliminada totalmente; sólo se puede evolucionar a partir de ella. «Hasta el torpe cadáver que las palabras / hilan ha de ser hijo de una realidad anterior en 
el tiempo» escribió Carnero en ese libro de poemas, proclamando la obviedad de que nada surge per se, de que todo tiene un origen inevitablemente anterior. «Envejecer, morir, es el único argumento de la obra» ${ }^{3}$, había escrito Gil de Biedma años antes, y a grandes rasgos es lo que el autor de los poemas de esta antología transmite en su primer libro. Cargado de un profundo simbolismo como lo único hermoso, incluso a la hora de representar la muerte, va mucho más allá de lo real, que a veces resulta alegoría, en palabras del poeta, «no de la nada, sino de nada». Recupera la estética poética, la belleza de escribir, más allá de la obsesión realista de la poesía de posguerra, que pierde todo su sentido lírico y se centra en su afán de denuncia. Todo esto quizá suene a la expresión de el arte por el arte, como paradigma de la libertad del arte como concepto independiente de la realidad.

Los símbolos de muerte se repiten una y otra vez a lo largo de toda la selección de poemas de Dibujo de la muerte, y las reflexiones sobre ello. Viene representada tanto por un gondolero y su góndola en el poema «Venecia», como de manera recurrente en la imagen del mármol y las losas, de las tumbas que encierran los cadáveres una vez rebosantes de vida; en los poemas «Ávila», «Boscoreale y Bacanales en Rímini para olvidar a Isotta», son prácticamente protagonistas de los versos. Carnero no sólo habla de la muerte, su inevitabilidad y su ironía, sino que también asume que es parte de la vida: «si me fueran / concedidas las riendas de la inmortalidad, sé que las dejaría / caer», dice en «Panorama desde la Tour Farnèse»: ¿tendría la vida el mismo sentido, la viviríamos con la misma intensidad sabiendo que lo que nos rodea, así como nosotros mismos, no es perecedero? Si la inmortalidad no está hecha para el ser humano, quien guarda en su interior el fuego de vivir con intensidad -a pesar de que nos encontremos en los tiempos de la vida light que nunca profundiza más de lo debido- y el fin es inevitable, «¿Por qué no subir, si todo está perdido?» si, como transmite en el poema «Movimiento continuo», la vida no es más que un circo, una atracción de feria, que gira imparable hacia la muerte. Será en el apartado casi final de Variaciones y figuras... donde se hable de lo inmortal como patrimonio de lo muerto, en Dibujo de la muerte hace referencia a ello: «eternamente jóvenes / eternamente vivos, eternamente vivos como en el primer día, debajo de la máscara / y ni fuego ni muerte ni curso de las horas / habitarán jamás este salón», porque aunque el tiempo no se pueda detener para evitar la muerte, paradójicamente es ella quien detiene el tiempo, quien mantiene eternamente joven a quien así muere y une para siempre a quienes yacen en tumbas contiguas en el mismo mausoleo.

4 Si la conclusión de todo es que sólo hay dos cosas inevitables: vivir y morir, ¿cuál es la recompensa a todos los días vividos? «¿todo el triunfo es ese, ser contemplado, cuerpo / ya ausente de vida, mirto, laurel, exangües / torpes máscaras tintas en os seniles fastos / las lágrimas, el vino?», pregunta en "Carnaval en el sur». ¿Se mide el triunfo de la vida en cuánta gente acuda a nuestro entierro? Si nuestros logros en vida serán irremediablemente perdidos, si nuestros esfuerzos serán inútiles -como los de la «estrella apagada que seguía su órbita concienzudamente $»^{4}$ en el poema de Huidobro- y estamos condenados nada más nacer. Este sabor amargo y a la vez resignado nos deja Dibujo de la muerte. Cabe destacar el empleo de la técnica del culturalismo, es decir, alusión a personajes, situaciones, frases, que el poeta toma de la historia de la cultura y que por su cuenta recrea para hacerlos portavoz de sus propias intuiciones.

5 Se incluyen también en esta antología poemas recogidos de su libro El sueño de Escipión (1971) considerado como una de las reflexiones más inteligentes y profundas sobre el acto de creación poética. El tema central del libro es el reconocimiento de la mezquindad 
constitutiva del escritor, que utiliza la cochambre de su propia experiencia para convertirla en poemas estéticamente bellos -parafraseando una de las notas escritas por el editor de esta antología, Ignacio Javier López-, y que expresa explícitamente en su poema «Erótica del Marabú». El marabú es un ave que para Carnero representa de manera absoluta la sordidez del arte de escribir poesía, y de la vida en general («nuestro pan de cada día»): se trata de un ave de rapiña, pero cuyas plumas son muy apreciadas en la alta costura. El hecho de que de la muerte y la putrefacción surja la belleza y lo deseado se aplica al arte de escribir poesía, que no es más que transformar nuestros propios cadáveres -nuestros episodios fallidos, la gente que quedó atrás, lo inevitable de la vida, lo grotesco- en algo bello, pese a lo triste que pueda ser lo que se cuenta en esas líneas.

6 También se centra en reflexiones metapoéticas como lo vacío de las palabras cuando se intentan limitar al nexo de significante-significado, y lo lejos que pueden llegar a estar de lo que la música puede transmitir a las emociones, aunque sobre esto hablará más explícitamente en otro libro: «su vocabulario son recuerdos porosos». Compara el lenguaje con los recuerdos, que no son ni una aproximación de lo que fue la realidad: «así tu cuerpo fue. Y recordarlo ahora / es un mundo sin eco, una ciudad vacía», dice en «Jardín Inglés», metáfora del jardín interior del poeta, ese lugar abstracto donde desarrolla su yo. La reflexión metapoética está expresada de una manera más contundente en "Chagrin d'amour, principe d'œuvre d'art», además de reflexiones sobre la vida, con versos como: «banalidad sin duda / y humildad de vivir: una falta de gusto», que recuerda también a Gil de Biedma: «Oh innoble servidumbre de amar seres humanos, / y la más innoble / que es amarse a sí mismo! $»^{5}$, y un consuelo ante la inevitabilidad del óbito: «porque el amor nos salva: no haber vivido en vano».

El culturalismo sigue presente, con referencias a personajes históricos o incluso a cuentos de los hermanos Grimm. Un poema, «Cenicienta», aúna tres de ellos -la Cenicienta, Blancanieves y la rana que se convierte en príncipe-, y Carnero transforma a la Bella en Bestia y, lejos del ideal romántico de la mujer noble y buena que introduce su delicado pie en el zapato de cristal, dibuja a la causa de destrucción del hombre y la causante de la transformación de los príncipes en ranas. Quizá este golpe de realidad choque con las pretensiones novísimas de alejamiento de ésta, o quizá también surgieron en él las ganas de derrumbar mitos como la idealización de la mujer, pasándose al extremo opuesto. El culturalismo toma en estos poemas un calificativo: ficticio. Según el propio poeta, el culturalismo ficticio «consiste en la introducción de referentes culturales inventados, pero siempre posibles y verosímiles. Lo motiva una necesidad expresiva que desea contar con los matices analógicos que dichos referentes hubieran aportado, en el caso de haber efectivamente existido».

8 En Variaciones y figuras... «plantea uno de los grandes motivos de lo que se ha denominado la posmodernidad: la sensación de que el poeta se encuentra en un momento de crisis al vivir en una época de agotamiento cultural (...) pesa de tal modo sobre el presente que el poeta carece de entusiasmo para introducir novedades. Lo más a que puede aspirar éste es a reformular metódicamente las ideas del pasado», según el editor. En resumen, se trata de la falta de esperanza en la poesía y la cultura, dado el ínfimo interés de la sociedad misma tanto en su creación, como en su consumo. Carnero habla de «cuando creemos estar vivos, envueltos en palabras como velos» en su poema «Domus Áurea», del mundo posmoderno encerrado en sí mismo, perdido creyendo ser tanto como a la vez no es, envuelto en sus propias creencias y anestesiado en su falsa seguridad. El simbolismo de Carnero permite tanto múltiples lecturas como ninguna, pero es suficiente que se nos 
insinúe una de ellas para que nosotros mismos seamos capaces de entrever lo que con su nada puede transmitirnos, sin alejarse de la belleza y su arte por el arte.

Su obra cae en la reflexión filosófica en El azar objetivo (1975), donde la muerte del pensamiento y la falta de esperanza cultural siguen siendo grandes protagonistas. En «Museo de Historia Natural» puede percibirse una metáfora sobre aquellas personas que más que personas no queda de ellas más que su concepto («no es más que el concepto de boa»), consecuencia de vivir envueltos en esas palabras y en esas creencias que aligeran el peso de nuestra propia vida (quizá seamos tan sólo cadáveres, como escribió Dámaso Alonso); la sumisión al discurso lógico y tantas veces inútil descrito y parodiado en los poemas «La búsqueda de la certeza» y «La meditación de la pecera». Trata también el aspecto de la creación y el origen del arte, como consecuencia de la memoria y de un factor -desconocido incluso para el propio artista- que, no se sabe cuándo ni cómo, desordena toda esa memoria y, de forma azarosa, da como resultado la obra final.

Los poemas seleccionados para el apartado final del libro son los correspondientes a Ensayo de una teoría de la visión (1977), donde Carnero fusiona sus temas fetiche -la muerte y la reflexión sobre la metapoética y el conocimiento- recogidos en sus libros anteriores. Respecto a la metapoética, caben destacarse reflexiones reflejadas en versos como: «me concedes el barro / en que reside el don de la palabra»-pudiéndose tomar el barro como alegoría de lo que aún no es pero puede llegar a ser: las palabras como el ingrediente fundamental para la construcción vital, para la invención y la creación de todo aquello que queramos o podamos imaginar- o «resumiendo: invertir / el proceso creador; no de la emoción al poema, sino al contrario». En este último verso puede vislumbrarse, quizá, algo del creacionismo de Huidobro, cuyo lema era «¿Por qué cantáis a la rosa, oh poetas? ¡Hacedla florecer en el poema!» ${ }^{6}$ y cuyo objetivo era, no reflejar la realidad, sino crearla en los propios versos. Así pues, Carnero hace una analogía de este creacionismo trasladando la realidad al mundo de las emociones, pudiéndose decir «ipor qué escribir lo que siento, pudiendo hacer sentir con lo que escribo?».

11 Finalmente, encontramos dos poemas relacionados con el primer poema de Dibujo de la Muerte, «Ávila: Convento de Santo Tomás», en el cual describe la irónica situación de verse describiendo un mismo lugar, reducto de muerte, cubierto del mármol que representa la eternidad de lo muerto; y «Catedral de Ávila», con la alegoría de las tumbas de los cadáveres como las estanterías que son tumbas para los libros sepultados bajo el peso de la posmodernidad que no deja sitio para la cultura. La sepultura encierra para siempre los cuerpos, y el poema encierra para siempre ese interés por la creación literaria: «cuando mi mano se detenga helada / un anaquel será mi sepultura-.»

Obviando el apéndice, resulta necesario señalar lo cíclico de esta antología, que comienza, continúa y acaba en muerte. Tal y como lo hace la vida, que, paradójicamente, no sería posible si fuera eterna. El apéndice recoge un único poema, con el cual se despide esta recopilación poética: «Une semaine de Bonté». Este poema deja, sin embargo, algo de esperanza entre lo amargo de la vida y la posmodernidad vacía: «Mientras arriba riges desde los cuatro vientos / el ondear polícromo de tu vocabulario». A pesar de todo, somos dueños de las palabras, y las palabras son ese barro con el que hemos de erigir la realidad, renovarla y no plasmarla, no heredarla sino mejorarla, no guardarla como un cómodo colchón donde dormir, sino ir más allá: crearla. 


\section{NOTAS}

1. Jose María Castellet, Nueve Novísimos Poetas Españoles, Barcelona, Ed. Barral, 1970.

2. Guillermo Carnero, Dibujo de la muerte. Obra poética (1966-1990), Madrid, Ed. Cátedra, 2010. Todos los versos de Carnero citados han sido extraídos de este libro.

3. Jaime Gil de Biedma, Poemas Póstumos. Las personas del verbo, Barcelona, Ed. Seix Barral, 1982.

4. Vicente Huidobro, Altazor. Temblor de Cielo, Madrid, Ed. Cátedra, 2009.

5. Jaime Gil de Biedma, Poemas Póstumos. Las personas del verbo, Barcelona, Ed. Seix Barral, 1982.

6. Vicente Huidobro, Arte Poética, http://www.vicentehuidobro.uchile.cl/poema6.htm

\section{AUTORES}

\section{MARÍA MOLINA DELICADO}

Universidad San Pablo - CEU de Madrid y de Filosofía en la UNED 